\title{
Socio-economic and demographic factors associated with adaptive behaviour among children diagnosed with autism spectrum disorder in Egypt
}

Nashwa Ibrahim $^{1 *}$ D, Asmaa Maher Zein El-abdeen', Fiona $\mathrm{Ng}^{2}$, Mohamed Zoromba ${ }^{1}$ and Aml Haikal ${ }^{3}$

\begin{abstract}
Background: Adaptive behaviour among children diagnosed with autism spectrum disorder determines wide range of self-independent and autonomous activities. Adaptive behaviour is a clearly defined measurable variable that can be used as an outcome, hence impacts intervention and training programs. The current study aims to determine the socio-economic and demographic factors that are associated with adaptive behaviour among children diagnosed with autism spectrum disorder in Egypt. In this observational cross sectional study, caregivers' reports on their children with a confirmed diagnosis of autism spectrum were obtained. Vineland Adaptive Behaviour Scale was used to assess adaptive behaviour among children aged 3-6years and admitting at the outpatient clinic. Socioeconomic Status Scale was used to assess family socioeconomic status.
\end{abstract}

Results: Participants in the current study scored low in domains of adaptive behaviour. Older children scored low in adaptive behaviour compared to younger children. There was significant positive correlation between daily living activities subdomain of adaptive behaviour and education, occupation, family possessions, and home sanitation and health care domains of socioeconomic status scale. There were significant positive correlations between socialization subdomain of adaptive behaviour and education, occupation, family, and family possessions and home sanitation domains of the socioeconomic status scale. The motor functioning subdomain of adaptive behaviour correlates significantly with the following SES domains: education $(r=.268)$, occupation $(r=.274)$, family possessions $(r=.232)$, economic $(r=.195)$ and health care $(r=.291)$. Results of the current study revealed that high socioeconomic status correlates with higher adaptive functioning in daily living skills, socialisation and motor skills domains of adaptive behaviour.

Conclusion: The correlations detected in the current study between adaptive behaviour and some social determinants of health can influence stakeholders' decisions in planning and implementation of autism specific interventions.

\footnotetext{
* Correspondence: Nashwa_2005@mans.edu.eg

${ }^{1}$ Psychiatric and Mental Health Nursing Department, Faculty of Nursing,

Mansoura University, Mansoura, Egypt

Full list of author information is available at the end of the article
}

\section{Springer Open}

( ) The Author(s). 2020 Open Access This article is licensed under a Creative Commons Attribution 4.0 International License, which permits use, sharing, adaptation, distribution and reproduction in any medium or format, as long as you give appropriate credit to the original author(s) and the source, provide a link to the Creative Commons licence, and indicate if changes were made. The images or other third party material in this article are included in the article's Creative Commons licence, unless indicated otherwise in a credit line to the material. If material is not included in the article's Creative Commons licence and your intended use is not permitted by statutory regulation or exceeds the permitted use, you will need to obtain permission directly from the copyright holder. To view a copy of this licence, visit http://creativecommons.org/licenses/by/4.0/. 


\section{Background}

The estimated prevalence of autism spectrum disorder (ASD) is approximately 1 in 68 children and is considered one of the most common chronic childhood disorders [1]. Functioning in ASD is compromised across different domains including adaptive behaviour. Adaptive behaviour refers to individuals' ability to achieve set of age related skills that enables them achieve independence [2]. Deficits in the area of adaptive behaviour are primary barrier to a wide range of activities that range from basic personal autonomy to self-sustainability [3]. Despite the ambiguity of factors that contribute to positive outcome in ASD, adaptive behaviour tends to be more clearly measurable positive outcome. Therefore, adaptive behaviour is linked to training and intervention programs to enhance independent living $[4,5]$.

Evidence shows that deficits in adaptive behaviour are more severe than cognitive deficits in ASD. Therefore, adaptive skill development ascertains levels of independence, supervision and treatment planning of children with ASD [6, 7]. Several studies reported that although parents may notice autistic symptoms of their children early, they defer professional help until children reach 3-6 years old. Early detection and management for children with ASD aged 3-6 years could improve their adaptive behaviour as reported in many studies [8].

The dearth of epidemiological data available on ASD in Egypt despite reports of increasing prevalence worldwide is a challenge for health and education provision [9]. Even with the increased importance of early diagnosis and intervention of ASD [10], socioeconomic variables can influence timing of the diagnosis of ASD [11]. Additionally, some cross-cultural variations were reported in observational studies in some defining behaviours of ASD [10]. Epidemiological studies help in defining the characteristics of children with ASD [12] and gain better understanding of the disorder [13] particularly with the underdeveloped health and social services [9] to inform policy and decision-making [14].

\section{Aim}

The current study aims to determine the socioeconomic and demographic factors that are associated with adaptive behaviour among children diagnosed with autism spectrum disorder in Egypt.

\section{Methods}

\section{Study design}

Observational cross-sectional research design was used in the current study.

\section{Participants}

Children were recruited immediately after a confirmed diagnosis of ASD by the consultant psychiatrist at children's outpatient clinic of psychiatry department, Mansoura University Hospital, where diagnosis of ASD followed the Diagnostic and statistical Manual of Mental Disorder, $5^{\text {th }}$ edition (DSM-5) and was documented in children outpatient medical charts. Diagnosis was not reconfirmed by the study research team. Children were recruited if their age ranged between 3 and 6 years, and their intelligence quotient (IQ) that is routinely assessed for all children by a psychologist at the clinic using the $5^{\text {th }}$ edition of the Arabic Stanford-Binet tests [15] was greater than 80 to control the confounding effect of IQ on adaptive behaviour. Children were excluded if they underwent any behavioural or pharmacological management for ASD (to control the outcome bias). If the attending psychiatrist at the clinic elicited any neurodevelopmental, behavioural or mental disorder during DSM-5 diagnostic screening, the child was excluded from recruitment in the study.

\section{Sample size calculation}

Records of the outpatient clinic revealed that approximately 400 child diagnosed with ASD visited the clinic in 2016. We used Steve Thompson equation [16] for calculating sample size:

$$
n=\frac{N \times p(1-p)}{\left[\left[N-1 \times\left(d^{2} \div z^{2}\right)\right]+p(1-p)\right]}
$$

where $N$ refers to the population size, $z$ is the degree of freedom for $95 \%$ significance, $d$ is the error percentage (0.05), and $p$ is the probability of occurrence of the event or not (0.5). The calculated sample size was 89 participants.

A total of 140 participants were approached with 90 caregivers of children with ASD agreeing to take part. Data was collected from January 2017 to January 2018.

\section{Measures}

Socio-economic status (SES) scale was originally developed by Fahmy and El Sherbini (1983) in Arabic to assess family socio-economic status. The scale was further extended and updated by El-Gilany and El-Wehady [17] to include seven domains in the updated versions: education and cultural, family, economic, family possessions, home sanitation and health care. Depending on the quartile of the calculated score, the scoring of the scale is classified to high, middle, low and very low socioeconomic status, and the Cronbach $\alpha$ of El-Gilany and El-Wehady is 0.66 .

Vineland Adaptive Behaviour Scale (VABS) was used to assess adaptive behaviour. The scale consists of five domains: communication, daily living skills, socialization, motor skills and one optional domain (maladaptive behaviour) that was not applied in the current study [18]. In the current study, we used the survey form of the 
scale that was validated and translated to Arabic by Aleteby (2004). The internal consistency of the Arabic scale as reflected in Cronbach $\alpha$ ranges between 0.86 and 0.97

Although severity of autism symptoms is not a target outcome in the current study, we decided to report severity of autism symptoms by using the Arabic version of Giliam Autism Rating Scale [19] to control the confounding effect of symptoms severity on adaptive behaviour.

\section{Procedure}

Parents who agreed to take part in the study and their children met the study inclusion criteria which had a choice to complete the questionnaires or have the researcher read it out to them.

\section{Analysis}

Data was analysed using the Statistical Manual for Social Sciences (SPSS) version 24. One sample KolmogorovSmirnov test was used to check data normality. Categorical data was described in number and percentages, while continuous variables were presented as mean \pm SD (standard deviation) for parametric data.

Student's $t$ test was run two compare the means of two groups, while analysis of variance (ANOVA) test was used to analyse differences among group means. Pearson's correlation was used to examine the correlation between continuous parametric data. Confidence interval (CI) was set at $95 \%$ and the statistical power at $80 \%$.

\section{Results}

The majority of children attending (74.4\%) were males, and the mean age of the sample was $4.33 \pm 0.89$ years. High levels of symptoms severity was detected in $31.1 \%$ of the sample, and $68.9 \%$ has moderate levels of severity.

The majority of the current sample (53.4\%) lives in very low and low socioeconomic levels, and nearly quarter of the sample live in moderate SES.

Participants had low levels of adaptive behaviour in communication, daily living skills and socialization. The

Table 1 Sex difference regarding adaptive behaviour

\begin{tabular}{lllll}
\hline $\begin{array}{l}\text { Domains of the } \\
\text { VABS }\end{array}$ & Sex & Mean (SD) & \multicolumn{2}{l}{ Test of sig. } \\
\cline { 4 - 5 } Communication & Males & $28.87(10.84)$ & .001 & .999 \\
& Females & $28.87(12.43)$ & & \\
Daily living skills & Males & $45.90(8.48)$ & .213 & .832 \\
& Females & $46.35(8.88)$ & & \\
Socialization & Males & $48.88(10.95)$ & 1.094 & .281 \\
& Females & $51.78(10.99)$ & & \\
Motor skills & Males & $44.99(10.23)$ & 1.236 & .225 \\
& Females & $48.26(11.21)$ & & \\
\hline
\end{tabular}

majority of participants (95.6\%) scored low in motor skills domain of adaptive behaviour.

There were no statistically significant differences between males and females in all domains of adaptive behaviour (Table 1).

Adaptive behaviour among the studied sample differs significantly according to age in all domains. Results show that children aged 3 years have higher level of adaptive functioning in domains of communication, daily living skills and motor skills compared to older children, except for children aged 5 years which have higher level of socialization (Table 2).

No statistically significant correlation was identified between communication subdomain of adaptive behaviour and all domains of socioeconomic status, except health care domain. There was significant positive correlation between daily living activities subdomain of adaptive behaviour and the following SES domains: education $(r=.394)$, occupation $(r=.318)$, family possessions $(r=.290)$, home sanitation $(r=.238)$ and health care $(r=.403)$.

There were significant positive correlations between socialization subdomain of adaptive behaviour and the following domains of SES: education $(r=.355)$, occupation $(r=.287$.), family $(r=.247)$, family possessions $(r=$ $.282)$ and home sanitation $(\mathrm{r}=.250)$ were identified.

The motor functioning subdomain of adaptive behaviour correlates significantly with the following SES domains: education $(r=.268)$, occupation $(r=.274)$, family

Table 2 Age difference in relation to domains of adaptive functioning

\begin{tabular}{|c|c|c|c|c|c|}
\hline \multirow{2}{*}{$\begin{array}{l}\text { Domains of the } \\
\text { VABS }\end{array}$} & \multirow[t]{2}{*}{ Age } & \multirow[t]{2}{*}{ Mean } & \multirow[t]{2}{*}{ SD } & \multicolumn{2}{|c|}{ Test of sig. } \\
\hline & & & & $\bar{F}$ & $p$ \\
\hline \multirow[t]{4}{*}{ Communication } & 3 years & 44.29 & 5.76 & 28.727 & $<.001$ \\
\hline & 4 years & 22.26 & 9.96 & & \\
\hline & 5 years & 27.55 & 7.24 & & \\
\hline & 6 years & 29.25 & 5.26 & & \\
\hline \multirow[t]{4}{*}{ Daily living skills } & 3 years & 58.71 & 7.09 & 34.030 & $<.001$ \\
\hline & 4 years & 42.79 & 6.98 & & \\
\hline & 5 years & 44.23 & 4.13 & & \\
\hline & 6 years & 39.63 & 2.39 & & \\
\hline \multirow[t]{4}{*}{ Socialization } & 3 years & 53.94 & 11.55 & 23.079 & $<.001$ \\
\hline & 4 years & 41.44 & 9.22 & & \\
\hline & 5 years & 57.58 & 5.03 & & \\
\hline & 6 years & 44.38 & 5.78 & & \\
\hline \multirow[t]{4}{*}{ Motor skills } & 3 years & 62.47 & 6.00 & 41.925 & $<.001$ \\
\hline & 4 years & 41.24 & 7.30 & & \\
\hline & 5 years & 42.87 & 6.68 & & \\
\hline & 6 years & 41.38 & 6.86 & & \\
\hline
\end{tabular}


Table 3 Correlation between adaptive functioning and domains of socioeconomic status of studied children

\begin{tabular}{llllll}
\hline & & Communication & Daily living skills & socialization & Motor skills \\
\hline Education & $r$ & .096 & .394 & .355 & .268 \\
Occupation & $r$ & .173 & .318 & .287 & .247 \\
Family & $r$ & -.148 & .158 & .290 & .282 \\
Family Possessions & $r$ & -.046 & .193 & .176 & .232 \\
Economic & $r$ & -.045 & .238 & .250 & .195 \\
Home Sanitation & $r$ & -.049 & .403 & .163 & .129 \\
Health care & $r$ & .262 & & & .291 \\
\hline
\end{tabular}

possessions $(r=.232)$, economic $(r=.195)$ and health care $(r=.291)$ (Table 3).

High socioeconomic status correlates with higher adaptive functioning in daily living skills, socialisation and motor skills domains of adaptive behaviour (Table 4).

\section{Discussion}

The current study sought to determine the socioeconomic and demographic factors that are associated with adaptive behaviour among children diagnosed with autism spectrum disorder in Egypt before undergoing behavioural of pharmacological treatments.

Despite the absence of cognitive impairment in the current sample, findings reveal decline in adaptive behaviour domains in older children compared to younger children which is similar to other findings $[20,21]$. Considering that all children in the current study are newly diagnosed

Table 4 Differences of adaptive functioning related to socioeconomic levels of children

\begin{tabular}{|c|c|c|c|c|c|}
\hline \multicolumn{2}{|c|}{ Domains of the VABS } & \multirow[t]{2}{*}{ Mean } & \multirow[t]{2}{*}{ SD } & \multicolumn{2}{|c|}{ Test of sig. } \\
\hline & & & & $F$ & $P$ \\
\hline \multirow[t]{4}{*}{ Communication } & Very low & 29.22 & 8.96 & .404 & .750 \\
\hline & Low & 27.80 & 10.34 & & \\
\hline & Moderate & 27.73 & 9.58 & & \\
\hline & High & 31.05 & 15.80 & & \\
\hline \multirow[t]{4}{*}{ Daily living skills } & Very low & 42.57 & 10.23 & 6.098 & .001 \\
\hline & Low & 44.32 & 6.63 & & \\
\hline & Moderate & 45.82 & 6.57 & & \\
\hline & High & 52.30 & 7.54 & & \\
\hline \multirow[t]{4}{*}{ Socialization } & Very low & 43.35 & 10.89 & 4.756 & .004 \\
\hline & Low & 49.00 & 11.13 & & \\
\hline & Moderate & 53.36 & 9.41 & & \\
\hline & High & 53.50 & 9.57 & & \\
\hline \multirow[t]{4}{*}{ Motor skills } & Very low & 42.70 & 11.75 & 2.756 & .047 \\
\hline & Low & 43.60 & 8.19 & & \\
\hline & Moderate & 47.18 & 10.23 & & \\
\hline & High & 50.70 & 10.64 & & \\
\hline
\end{tabular}

with ASD, this result presents implications for early diagnosis and intervention research for children with ASD particularly among families living in low and very low socioeconomic status that is the case of the current sample.

The statistical correlation detected in the current study between adaptive behaviour and SES is consistent with Pickard and Ingersoll [22]. Children who live in high SES are more likely to receive earlier diagnosis than those from lower SES and may benefit from some privileges like access to social and sport clubs which may influence domains of adaptive behaviour.

The current study reported positive correlation between domains of adaptive behaviour and some domains of SES. The correlation may be linked to social determinants of health. Variability in parents' education, income, occupation and home sanitary conditions may influence access and utilization of health services, views and engagement in treatment [23]. The restricted governmental resources offered to children with ASD in Egypt add high burden on families of children with ASD. Nearly 83.3 to $91.3 \%$ of people with ASD in Egypt reside with their families even during their adult life [24].

The implication of the current study is translating its findings alongside larger epidemiological studies into policy action to broaden clinical perspectives. Considering the social context of children with or at risk for ASD in Egypt will inform stakeholders about the changes that need to be made in every situational context [25].

\section{Conclusions}

The current study reported correlations between domains of adaptive behaviour and domains of the socioeconomic status of families of children diagnosed with autism spectrum disorder. Interventions targeting adaptive behaviour could be tackling such social determinants of health.

\section{Limitations of the study}

The small sample size in the current study that is likely to influence generalisation, the single setting of data recruitment and the reporting bias (caregivers' reports only) as data was based solely on caregivers' reports which are limitations of the current study. 


\section{Abbreviations}

ASD: Autism spectrum disorder; SES: Socio-economic status; VABS: Vineland Adaptive Behaviour Scale

\section{Acknowledgements}

We would like to acknowledge and thank all participants in the current study for their valuable time.

\section{Authors' contributions}

$\mathrm{Nl}$ performed the conceptualization, methodology and writing of the original draft. AZ performed data collection. FN performed writing, review and editing. $M Z$ performed the formal analysis. AH performed the conceptualization and supervision. All authors have read and approved the manuscript.

\section{Funding}

We did not receive any funding for this research

\section{Availability of data and materials}

Data is available upon request.

\section{Ethics approval and consent to participate}

Faculty ethical approval was obtained (no reference number available), and all participants in the current study gave informed written consent to take part.

\section{Consent for publication}

Authors agreed to publishing this manuscript in the journal after reviewing the final version.

\section{Competing interests}

The authors declare no competing interests.

\section{Author details}

${ }^{1}$ Psychiatric and Mental Health Nursing Department, Faculty of Nursing, Mansoura University, Mansoura, Egypt. ${ }^{2}$ School of Health Sciences, Institute of Mental Health, University of Nottingham, Nottingham, UK. ${ }^{3}$ Psychiatry Department, Faculty of Medicine, Mansoura University, Mansoura, Egypt.

Received: 4 June 2020 Accepted: 14 July 2020

Published online: 15 September 2020

\section{References}

1. Dellapiazza F et al (2018) Links between sensory processing, adaptive behaviours, and attention in children with autism spectrum disorder: A systematic review. Psychiatry Res 270:78-88

2. Ashwood KL et al (2015) Brief report: Adaptive functioning in children with ASD, ADHD and ASD+ ADHD. 45(7):2235-2242

3. Mouga $S$ et al (2015) Adaptive profiles in autism and other neurodevelopmental disorders. J Autism Dev Disord 45(4):1001-1012

4. Kanne SM et al (2011) The role of adaptive behavior in autism spectrum disorders: Implications for functional outcome. 41(8):1007-1018

5. Farley MA et al (2009) Twenty-year outcome for individuals with autism and average or near-average cognitive abilities. 2(2):109-118

6. Liss M et al (2001) Predictors and correlates of adaptive functioning in children with developmental disorders. 31(2):219-230

7. Golya, N., L.L.J.J.o.i. McIntyre, and d. disability, Variability in adaptive behaviour in young children with autism spectrum disorder. 2018. 43(1): p. 102-111.

8. Wang J et al (2012) Autism awareness and attitudes towards treatment in caregivers of children aged 3-6 years in Harbin, China. 47(8):1301-1308

9. Gobrial E, McAnelly S, Shannon P (2019) Education of children and young people with autistic spectrum disorders in Egypt. Br J Learn Disabil 47(1):29_ 34

10. Franz L, Dawson GJPM (2019) Implementing early intervention for autism spectrum disorder: a global perspective. 2

11. Wiggins LD et al Disparities in documented diagnoses of autism spectrum disorder based on demographic, individual, and service factors. Autism Res

12. Bakare MO, K.M.J.A.j.o.p. Munir (2011) Autism spectrum disorders (ASD) in Africa: a perspective. 14(3):208-210

13. Honda, H.J.B. and Development (2013) How can epidemiological studies contribute to understanding autism spectrum disorders? 35(2):102-105
14. El Razik MSA, Salem MR (2019) From public health and demographic research to decision making: An intervention study in Giza GovernorateEgypt. Eval Program Plann 77:101704

15. Farag, S.J.C., Egypt: Anglo Press. Back to cited text, Stanford-Binet Intelligence Test: Standardized Arabic Version. 2011(12).

16. Thompson, S.K., Sampling. Third edition ed. CourseSmart. 2012: Wiley, Hoboken. 445.

17. El-Gilany A, El-Wehady A, El-Wasify M (2012) Updating and validation of the socioeconomic status scale for health research in Egypt. East Mediterr Health J $18(9)$

18. Sparrow, S., O. Balla, and D.J.C.P. Cicchetti, MN: AGS, Vineland Adaptive Behavior Scales (VABS): Interview edition. 1984

19. Abdelrahman M, Hasan M (2004) Gilliam autism rating scale arabic version. Dar El-Sahab press, Cairo

20. Klin A et al (2007) Social and communication abilities and disabilities in higher functioning individuals with autism spectrum disorders: The Vineland and the ADOS. 37(4):748-759

21. Szatmari P et al (2003) Predictors of outcome among high functioning children with autism and Asperger syndrome. 44(4):520-528

22. Pickard KE, Ingersoll BRJA (2016) Quality versus quantity: The role of socioeconomic status on parent-reported service knowledge, service use, unmet service needs, and barriers to service use. 20(1):106-115

23. Zuckerman KE et al (2015) Parent health beliefs, social determinants of health, and child health services utilization among US school-age children with autism. 36(3):146

24. Mendoza, R.L.J.A.J.o.E. and B. Administration (2010) The economics of autism in Egypt. 2(1):12

25. McClure, R.J., T.M.J.A.S.P.A.J.o.I. Davey, and V. Prevention, Implementation epidemiology: The study of the frequency, distribution and determinants of effective prevention practice. 2013. 11(1): p. 3-12.

\section{Publisher's Note}

Springer Nature remains neutral with regard to jurisdictional claims in published maps and institutional affiliations.

\section{Submit your manuscript to a SpringerOpen ${ }^{\circ}$ journal and benefit from}

- Convenient online submission

- Rigorous peer review

- Open access: articles freely available online

- High visibility within the field

- Retaining the copyright to your article

Submit your next manuscript at $>$ springeropen.com 